\title{
Looking Back from 2046: Thoughts on the Eightieth Anniversary of an Institute for Revolutionary Social Science
}

\author{
Michael Edwards
}

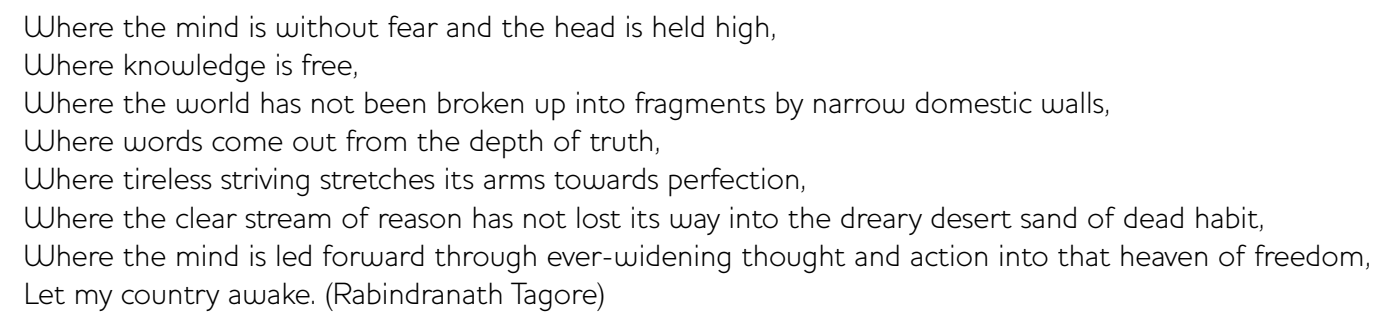

All of us who attended or are interested in the IDS40 conference are exploring the 'country' that Rabindranath Tagore describes in his poem, and we know how difficult and demanding that journey can be. This is especially true today, though here I can be accused of being overly influenced by the context in which I live and work - the USA - where facts, objectivity, proof, accumulated wisdom, public debate, accountability, the careful calculation of risks and benefits, and the other pillars of effective policymaking we have been gradually piecing together since the Age of the Enlightenment are increasingly up for grabs. Let decisions be driven by ideology, faith, speculation, greed, graft and revenge. Let truths be revealed rather than negotiated. In modern politics, or at least in this form of modern politics, facts are for losers.

Sadly, social science has rarely been important to social transformation, inside the USA or without. We dream of a world ruled by love and reason, only to wake up to a reality driven by ideology, prejudice and power, exercised with a calculated and systematic rawness that challenges even the most optimistic of optimists. Knowledge that supports or confirms these positions will be raised up, while knowledge that challenges them will be ignored or de-legitimised. But this is partly our fault, since we have not devoted sufficient energy and imagination to closing the gap. I do see knowledge as a necessary if not sufficient condition for effective personal, private or public action. 'Books don't change things', as a Brazilian philosopher once said, 'people do, but books change people'.

We want to do better, and can do better, without surrendering to the temptations that come from proximity to influence, money and popularity. That is the mission of 'revolutionary social science' (as I am going to call it here), in support of Lawrence Haddad's injunction not to rest on our laurels, but to go much further even than our current aspirations for development studies might suggest. And I want to start by saluting the progress that IDS has already made in transforming itself into a vibrant and selfcritical institution, exemplified by the process it embarked upon for its fortieth anniversary. I cannot think of many other institutions that would have had the courage and foresight to celebrate their anniversary in this way, and none at all in the USA.

To start with, I think we have to reach a position on the 'big' questions before discussing the detail of research issues, methods and strategies, otherwise only incremental improvements are possible within 
the current but unsatisfactory paradigms in which we work. Organisational change is usually easier when you hammer out a long-term vision that keeps everyone's 'eyes on the prize', while your inevitable differences are negotiated at the next level of detail, and you have time to put in place a gradual strategy for re-tooling the organisation in terms of staffing, structures and funding. Otherwise, those differences have a nasty habit of taking over the conversation completely.

For me, the three big questions are: first, 'development' vs. social transformation - what is the best conceptual and analytical frame in which to do our work going forward? Second, are we co-creators of knowledge, or do we see the world divided up between producers and consumers? And third, is our role to deliver academic products or to utilise knowledge in facilitating the essential public work of democratic deliberation and problemsolving? Our answers to these questions will determine what we do on a day-to-day or week-toweek basis in setting out plans and priorities over the coming years. I will now explore each of these questions in more detail before moving to specifics.

First, is there really enough mileage left in the North-South paradigm to get us where we want to go? In his introduction to the IDS fortieth anniversary conference, Lawrence Haddad suggested there is a widespread dissatisfaction with the traditional framework of development studies and argued for the analysis of common and interlocking patterns of global social change through 'a family of development stories that can learn from each other'. I think the real problem with this is the foreign aid or intervention paradigm and the values and attitudes that lie behind it, rather than 'development' as an objective concept. It is these values and attitudes that divert our discipline from how we might want it to be defined, i.e. by its influence over the actions of the strong, to how its subjects actually experience it - as defined by its influence over the weak. Nevertheless, development and foreign aid are too strongly linked to be easily separated, so now is surely the time to replace this frame with a new vision for development studies as a constantly unfolding critical conversation about the ends and means of the 'good society' at every level of the world system. In other words: you can jump, the water is safe.

The question that puzzles me is: 'What do we have to lose?' There would be some challenges to our identity and funding streams in the short term, but that appears to be all. You do not have to stop doing research on Africa or on poverty, or be blind to the fact that certain problems are more acute in certain parts of the world or among particular groups. You do not have to abandon thoughts of progress, or positive social change, or subscribe to a particular political worldview. All you have to do is to recognise that problems and solutions are not bounded by artificial definitions of geography or economic condition, and to reposition yourselves as equalminded participants in a set of common endeavours. $\mathrm{HIV}$-infection rates, for example, are as high among certain groups of African-American women in the USA as in sub-Saharan Africa, and for similar reasons. The erosion of local public spheres is linked to decisions made by media barons in Italy, Australia and the USA. And, given the increasingly differentiated interests within the larger and faster-growing 'developing' countries like Brazil, China, India and South Africa, it is difficult to see why Chad or Myanmar would be included as comparators but Appalachia, Belarus, the Mississippi delta or the Ukraine would not.

A shift away from conventional thinking would generate a better understanding of causes and solutions since they are increasingly integrated across borders and disciplines, and revolve around common if differently experienced patterns of change and the capacity to control it. And it would be more influential with decision-makers, who do not read the development literature but do read op-eds, policy briefs and the occasional potboiler on security threats, terrorism, climate change, immigration reform, energy policy, clashing civilisations, and how to settle conflicts, achieve growth with equity, humanise capitalism, build community and deepen democracy. Unless they are Ministers of

Development or maybe friends of Bono or Jeffrey Sachs, they do not look to development research to provide guidance on any of those questions.

The second big question asks: 'Are we co-creators of knowledge or practitioners of detached scholarship that divides the world into producers and consumers? Is our aim to strengthen pockets of knowledge connected to decision-making elites, or is it knowledge and capacity broadly dispersed throughout society in order to underpin democratic processes of influence, problem-solving, mediation and accountability? Should knowledge be produced and owned by credentialed, 
detached experts, or are there many legitimate ways of knowing and multiple mechanisms that can facilitate the creation and sharing of knowledge among many different contributors?'

The implications for an institution like IDS are just as challenging, but by opening up the enterprise of knowledge to a broader range of actors, we can increase the chances of success because of the multiplier effects that flow from a larger number of channels through which knowledge connects to action and decision-making. 'Whether you are co-editing a volume', says Harry Boyte of the University of Minnesota, 'or organising to keep a waste incinerator out of your neighbourhood, cooperative labour means respectfully negotiating your differences and collectively putting your shoulders to the wheel. It means allowing for the fullest possible play of individual ideas, methods, goals and desires for the best of these to be selected without alienating your co-workers'. Common sense perhaps, but also threatening to us 'professionals', since 'nothing is so unsettling to a social order as the presence of a mass of scribes without suitable employment and an acknowledged status', a wonderful quotation from Eric Hoffer's book, The Ordeal of Change.

My third big question, closely related to the second, concerns the purpose of institutions like IDS: 'Does knowledge have a social purpose in animating the public sphere, or is it essentially a private activity that produces insights, increasingly on a commercial basis, for others in academia, or government or private sector clients?' We know that active social learning writ large is the only basis for democratic governance through deliberation and consensusbuilding, but technocratic approaches to knowledge breed technocratic approaches to politics, and we all suffer the consequences. It is no coincidence that America's public sphere has been hollowed out, elite control over public policy strengthened, and the country's ability to resolve pressing problems like healthcare and social security weakened, at the same time as social science in the USA has steered further and further away from the public, and closer to purely theoretical concerns, rational choice analysis and so on. Note the excitement over just this issue that greeted Michael Buroway's presidential address to the American Sociological Association in 2004, echoing debates over the supposed 'impasse in development theory' that took place during the late 1980s and early 1990s.
One after another, our democracies are being hollowed out and segmented in ways that prevent any genuine articulation of the public interest, reducing the chances still further of large-scale social, economic and political reform. The cultivation of critical thinking and deliberative skills among the broad population is fundamental to deep democracy, and knowledge, of all different kinds, is essential to that task. Of course, intellectuals, even public ones, are not the only knowledgeable occupants of the public sphere investigative journalists, advocacy non-governmental organisations (NGOs), bloggers, public radio stations and many others are also involved, but academics have a particular role to play in anchoring these other knowledge actors in the bedrock of rigour and independence, a subject which shall be returned to later

Once these questions have been answered, strategies, solutions and priorities become more obvious at the next level of detail. Let us assume therefore, that each of them is answered in the affirmative, i.e. that the frame we are using is social transformation not development; that we are co-creators of knowledge, not producers and consumers; and that engagement in the public sphere is a good way to promote a closer relationship between knowledge and social transformation. That is, I think, a pretty good recipe, for revolutionary social science, but what would it mean for the 'what, how, who and when' of the research we are going to do? What are the practical implications?

First - what to research? I am not sure there are huge new issues to be researched or discoveries to be made in development studies (technological innovation notwithstanding). But there are certainly better ways of looking at old and familiar issues about governance, institutions, poverty, power, diversity and difference and so on, or more broadly, how to facilitate an interlinked attack on inadequacies in the polity, inequalities in society and inefficiencies in the economy, and retain the environmental integrity of the planet in the process. Easy stuff really!

In that respect, I would argue for more 'symphonic poems', to use a musical analogy, and fewer endless variations on a theme - or even worse, proliferations of disassembled parts for particular instruments. I am not arguing for more 'symphonies' in development studies - more universal abstractions in other words, devoid of grounding in empirical detail - but more systematic efforts to make the connections, to 
identify patterns of cause and effect across time and space, to place individual experiences in their wider context, to help people sift through the costs and benefits of policies and actions, and to challenge accepted orthodoxies on urgent issues like dealing with difference; the changing roles of states, markets and civil society; and how to build new sources of legitimate authority to create and enforce norms and regulations in multipolar, multilayered governance regimes at all levels of the world system.

I think that, where we have been successful in promoting ideas over the last ten years, it has been at this level - changing the terms of the debate over globalisation and neoliberal economics, for example, cementing an intellectual commitment to participation and human rights as basic principles of development and development assistance, and keeping the spotlight on the need for reforms in global regimes and international institutions. Such 'symphonic poems' offer the most potential for influence because research has to be both sufficiently generalised to be relevant above the micro-level and sufficiently connected to the myths and memories, beliefs and ideologies, emotions and aspirations that drive people to take decisions and make changes. These patterns do not concern only huge global issues, but also lower-level, concrete problems that constantly reoccur when institutions face dilemmas of policy and action on a smaller scale. The problems of weak capacity and the under-funding of research institutions in the South are classic examples of issues such as this. It is obviously critical, we constantly complain about it and scratch our heads, and then devote almost no time or resources to actually pursuing the problem among researchers and funders alike. Why? Because it is not defined as sufficiently interesting or compelling by us.

In terms of how research is carried out and used, I think it is important to recognise that we cannot resolve the dilemmas of rigour and relevance in any absolute sense - but we can manage them more or less effectively. Once you look at these as management questions, rather than existential anxieties, it is surprising how quickly you can move to partial solutions. But they will always be partial, since researchers and practitioners inhabit different daily lifeworlds that impose different choices, incentives and timeframes on us, especially as the volume of information and speed of decision-making continue to increase. The trade-offs between these choices will obviously vary from one situation to another, but enough common ground and common purpose remain at the crossing points of these differences to make us valued collaborators, if that is what we want to be.

Over time we might meet in the middle ground and even fuse ourselves together as 'pracademics' or 'acadavists', but even if we do not, the important thing is to keep experimenting and trying things out, to keep edging forward, since even that would be a huge step away from the inertia and defensiveness that permeate most of academia today. In a recent report on higher education in the USA, Andy Mott of the Community Learning Project in Washington found that there were fewer universities offering courses that combined academic training with serious community engagement than there were in Iran when he taught there 30 years ago.

Part of the problem here is the persistent difficulty of legitimising different forms of knowledge and knowing: 'the gardening self, the person half-awake in bed, the woman who broods over old photos, and the madman' as Patricia Mclntosh once put it. Do we have the capacities to understand interpersonal as well as structural factors, politics as well as economics, global forces as well as local detail, history as well as the present, and to have a grasp of what might actually be possible in the circumstances as well as ideal?

It is easy for researchers to be shielded from these questions by a shallow but persuasive cleverness, just as activists sometimes take refuge in the safe but lazy demands of constant, unreflective engagement in the world (e.g. 'I'm way too busy, or too important, thank you very much, to think, read, or talk'). Amid these false polarities, it is tempting to use our skills and position as weapons to defeat or screen out the other, but in my experience, the compromises involved in forging genuine partnerships, and the desire to hold fast to values of inclusion, democracy and relevance, need do no significant damage to rigour.

As a non-academic, I want to make a special plea to preserve rigour and close attention to evidence, which may surprise some of you. Because of the political environment I sketched out earlier, rigour is even more important today, as long as it is not used as a weapon that 'destroys hope among activists', as Paulo Freire once warned. Rigour - the painstaking analysis of problems and solutions; the interrogation of all the evidence about costs and benefits, winners 
and losers; the ability to identify all the individual pieces of a puzzle and put them back together again into an accurate and coherent picture; the skills of presenting and comparing different theories of change; the depth of understanding built up by studying the same phenomena over long periods of time; the potential for accountability that results from a deliberate distancing of oneself from a predetermined ideological position - all these are crucial elements of revolutionary social science, and none of them necessarily involves a negative tradeoff between engagement and objectivity.

Often it is assumed that practitioners have no use for theory, but that is rarely true. Ernie Cortez (a longtime community organiser in the USA) for example, insists, in his training courses, on bringing the best theorists from political science, sociology and economics to talk with grassroots activists, and encourage them to interrogate all the different positions so they can turn their gaze towards local problems and solutions more effectively as a result. So it is not just the 'devil that's in the detail' as the old saying goes, but some possibilities for sainthood too. This is why I believe Lawrence Haddad is right to emphasise the core importance of independence.

How knowledge is used, of course, is just as important as how it is produced. Conventional answers to this question are sequential and elitist, which is why they do not work very well ('I'll produce the outputs, and then give them to you so you can take some action. Policy will change, and then practice'). This model is completely inadequate as a basis for influence, because it ignores the real drivers of change that require policy debates to be embedded in political processes and the activation of the polity. As a recent Canadian study points out, 'knowledge utilisation depends on disorderly interactions between researchers and users, rather than on linear sequences beginning with the needs of researchers or the needs of users. The more sustained and intense the interaction between researchers and users, the more likely it is that utilisation will occur' (Landry et al. 2003). In this frame, the purpose of the intellectual is not just to analyse and recommend policy, but to stimulate new conversations and help create a new sense of possibility beyond the given.

A key lesson from successful experiments in co-creation is that success is more likely when the participants agree to accompany each other over a substantial period of time, so that they can develop trust, mutual understanding and collaborative skills and commitments, and when they make more of their different skills and experiences, not less. Once that happens, you can usually sort out any problems that arise along the way, and together you have enough collective strength and maturity to face up to the deep prejudices and limitations that often block learning at the cutting-edge of social change.

It is the capacity to do this, not just rebuilding conventional but under-resourced universities or think-tanks that are important. So this dimension needs to be layered over the more basic inequalities that do require our urgent attention. Institutions of higher education are crucial because they give credence to knowledge, legitimise ways of knowing, generate and disseminate conceptual frameworks that help to structure development practice of different kinds, and they socialise professionals, so they are vital sites for transformation, but they are also highly resistant to change in ways that more resources are unlikely to influence. Therefore, we should also be looking to nurture new institutional forms that grow from different roots, being neither conventional research groups nor NGOs, but a mixture of both - 'distributed networks and coalitions for knowledge and action'.

I realise there are not many examples of such networks to choose from but there are promising partnerships, such as 'LogoLink', which was nurtured at IDS before its recent relocation to Brazil (an important case study of transferral I hope you will study and learn from); the International Budget Project with whom several IDS staff have been working, and the network on Facilitated Learning and Action for Social Change, which was initiated at an IDS workshop in March 2006. I mention these examples only because I know about them because of the Ford Foundation's involvement in them, not because this is a comprehensive list. The 'symphonic poems' I talked about earlier are the logical output of collaborations such as these. Indeed, it was through just these kinds of coalitions that conservatives gradually took over the intellectual and political agenda in the USA, although because they deliberately distorted knowledge for partisan purposes, I am not recommending that we copy their efforts wholesale. 'The new game in town', says the Washington Monthly (December 2003), 'is to dominate the entire intellectual environment in 
which decisions are made, which means funding everything from think-tanks to issue ads to phony grassroots pressure groups'. In contrast to that, I am talking about knowledge that facilitates a conversation rather than dominates the process and predetermines the outcome, but tactically, we have much to learn from the conservative experience.

For IDS, a useful way of looking at these questions may be to categorise your potential roles in promoting 'private reason' and 'public reason', or direct and indirect involvement in supporting knowledge for social change. Private reason covers the university's traditional roles as teachers and trainers of successive generations of active citizens, and as cherished zones of rational thought and independent criticism, able to exercise at least a modicum of accountability through the application of rigour to public policy problems. Not a bad thing to focus on, given the way the world seems to be heading.

Public reason covers the less traditional roles of knowledge institutions as co-creators, active in the public sphere. That might include an expansion of what you are already doing - to strengthen intermediaries, the translators of knowledge and bridges that use knowledge to influence policy and practice in directions that ultimately benefit defined causes or groups of people; and to build the knowledge-making and interpretative capacities of progressive groups and movements struggling for change, so that they can be more influential actors at higher levels of the political system. And it might include a louder public voice for development researchers, requiring a much more proactive and energetic role in publishing and speaking in the public media, including popular magazines and websites like OpenDemocracy, not just in specialist publications for the development set. This direct, public role has to be played very carefully lest it morph into speaking on behalf of others - but it can be done.

To conclude, it is worth asking whether development research does need to change. It certainly does not

\section{References}

Landry, R., Lamari, M. and Amara, N. (2003) 'The Extent and Determinants of Utilization of University Research in Government Agencies', Public Administration Review 63.2: 192-205, cited have to for financial reasons, at least in the short to medium term, since the revival of political support for foreign aid provides a continued security blanket for conventional development institutions, be they academic, think-tanks or NGOs. Development studies will linger on so long as the development paradigm survives, despite its shrinking significance geographically and continued marginalisation from the real centres of intellectual and political energy that drive change. There is still good money to be made from 'business as usual' on contract to the international aid system. So the motivation for change will have to come from within because you want to be an exemplar of what is possible on a much bigger stage, attained through a conscious, long-term strategy that maps out and manages the costs and risks involved.

Let me finish with a quote that I hope will give you courage to take that road into the future. It comes from an interview with Fred Halliday and published recently in the magazine Salmagundi, reminiscing about the first Chinese translation of the Communist Manifesto by students in Japan around 1910. Instead of 'workers of the world unite, you have nothing to lose but your chains', their version read 'scholars of the world unite, you have nothing to lose but your shame'!

'The shame', Halliday continues, 'is not doing the work. The shame is not listening to other people. The shame is not saying what you think. The shame is running after fashions of Left or Right. The shame is wasting your time in public, theatric pugilism.'

In some ways, we already have the antidote to shame of this kind - it lies in reasserting and defending the traditional virtues of rigour and independence in knowledge production. But we know that that is not enough. The task ahead is to marry these virtues with new and liberating experiments in co-creation and public work, so that, when we meet again in 2046, we will be able to celebrate the eightieth anniversary of something different and even more successful than IDS - an Institute for Revolutionary Social Science.

in Cohn, Daniel (2006) Jumping into the Political Fray: Academics and Policymaking, Montreal: Institute for Research on Public Policy Washington Monthly (2003) 'Meet the Press', December 